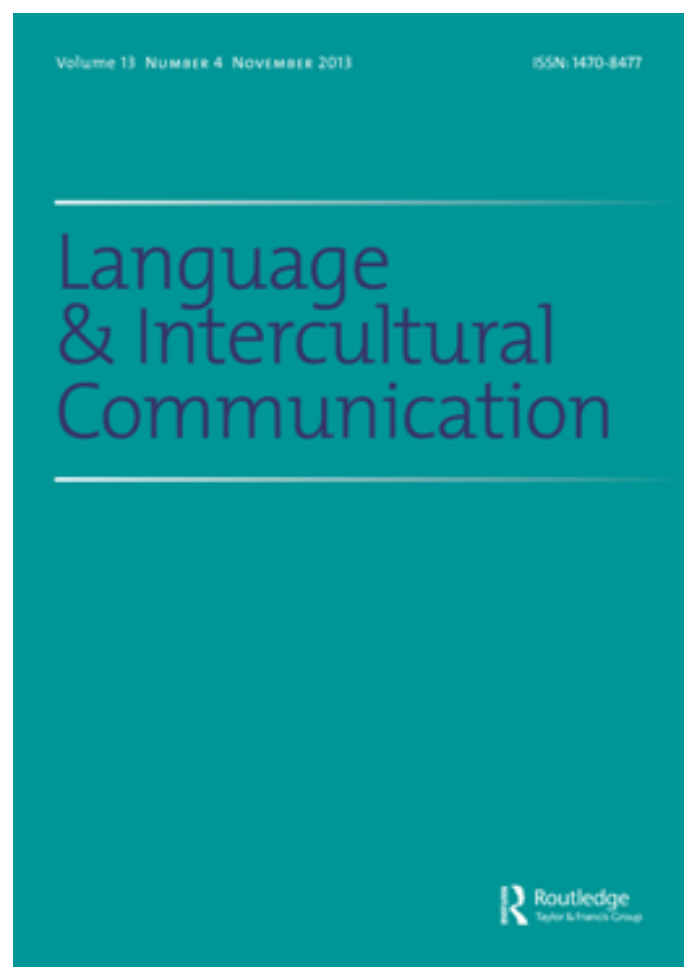

\title{
Tapping the thirdness in the intercultural space of dialogue
}

\begin{tabular}{|c|c|}
\hline Journal: & Language and Intercultural Communication \\
\hline Manuscript ID & LAIC-1171.R2 \\
\hline Manuscript Type: & Paper \\
\hline Keywords: & $\begin{array}{l}\text { dialogue, Intercultural communication, thirdness, in-betweenness, } \\
\text { hybridity }\end{array}$ \\
\hline Abstract: & $\begin{array}{l}\text { In this paper, we explore intercultural communication as dialogue } \\
\text { occurring in a third space. Through seven students' reflective essays on } \\
\text { group-based intercultural learning, we analyse the ever-shifting } \\
\text { communicative space that interlocutors produce through negotiating the } \\
\text { meanings of difference and power and their dialogic relations with the } \\
\text { other. Based on the findings, we propose intercultural dialogue (and } \\
\text { intercultural communication) as a political and ethical response to the } \\
\text { thirdness in the in-between space of communication, inherent in the } \\
\text { character of social life but not always possible nor desired. We therefore } \\
\text { suggest 'principles' for such dialogue be seen in this space and not as a } \\
\text { teleologically-achievable ideal that privileges self-expression and } \\
\text { normalises difference through a 'cultural diversity' discourse. }\end{array}$ \\
\hline
\end{tabular}

\section{SCHOLARONE Manuscripts}




\section{Tapping the thirdness in the intercultural space of dialogue}

In this paper, we explore intercultural communication as dialogue occurring in a third space. Through seven students' reflective essays on group-based intercultural learning, we analyse the ever-shifting communicative space that interlocutors produce through negotiating the meanings of difference and power and their dialogic relations with the other. Based on the findings, we propose intercultural dialogue (and intercultural communication) as a political and ethical response to the thirdness in the in-between space of communication, inherent in the character of social life but not always possible nor desired. We therefore suggest 'principles' for such dialogue be seen in this space and not as a teleologically-achievable ideal that privileges self-expression and normalises difference through a 'cultural diversity' discourse.

在此文中, 我们从第三空间对话的视角对跨文化交际进行探索。我们通过七个学 生关于团队作业中跨文化学习经历所撰写的反思性论文, 分析会话者对话语空间 的动态构建（其动态性涉及会话者对 ‘差异”与 ‘权力’ 的理解，和 ‘自我” 与 “他者” 的对话性关系)。基于此研究, 我们提出, 跨文化对话（以及跨文化交 际）应被理解为会话者对话语空间中 “第三性” 的政治、伦理回应。此回应源于 社会生活常态, 但并非存在/适用于任何具体情形。因此, 我们呼吁应当在此空 间中探索对话的 “原则” ，远离基于 ‘可习得” 交际能力和目的论的理想定义、 以及 ‘你说我说” 的谈话模式 (后者强调 “自我” 表达, 并且往往通过 ‘文化多 元论’ 对 ‘差异’ 进行规范化)。

Keywords: dialogue; intercultural communication; thirdness; in-betweenness; hybridity

\section{Introduction}

In this paper, we explore intercultural communication as dialogue occurring in a third space. The impetus for this study stems from the perplexity we experienced while supporting students' intercultural learning through a UK-based postgraduate module on 'developing intercultural competence'. This module was grounded in theories on 'intercultural competence' (e.g. Byram, 2003; Deardorff, 2006; Dervin, 2016), critical analysis of cultural 
essentialism (e.g. Holliday, 1999, 2011), and methodological frameworks (e.g. ethnography and narrative inquiry) for enquiry-based learning. Though not deeply discussed, 'dialogue' was used to indicate a desired intercultural learning activity, especially with reference to the Council of Europe's (2008, p.17) statement below:

Intercultural dialogue is understood as a process that comprises an open and respectful exchange of views between individuals and groups with different ethnic, cultural, religious and linguistic backgrounds and heritage [...] It aims to develop a deeper understanding of diverse world views and practices, to increase co-operation and participation, $[\ldots]$ to allow personal growth and transformation, and to promote tolerance and respect for the other.

Additionally, the module's learning objectives specified that students would engage in 'reflective dialogue with (their) own intercultural learning' experientially through groupbased assessment tasks. Students on this module were multinational (e.g. Germany, Italy, Switzerland, China, UK, Poland, USA, and Syria), varying in age, gender, professional experience, and main disciplines (e.g. culture, communication, marketing).

By creating a microcosm of 'culturally diverse', interdependent co-existence through an educational environment with 'intercultural learning' at its core, we hoped that students would contribute to their own, and our, knowledge of 'mutual understanding', 'tolerance', and 'harmonious interaction'. However, from their reflective essays on the learning experiences, we felt that the 'intercultural' environment, knowledge, and motivation we imagined to be in place did not clearly lend themselves to accounts of 'harmonious interaction'. Instead, frustration, distress, and mental retreats from relations of co-existence were not uncommon. In this paper, we draw on insights from theories particularly concerned with what happens in-between interlocutors in an attempt to interpret what was happening. From these, and from our data, we conclude, and also raise a number of concerns, on how intercultural communication can be conceptualised as dialogue in a third space. 
First, we consider the in-betweenness of intercultural communication particularly in relation to Homi Bbabha's (1994) Third Space of enunciation, and explore the roles cultural difference plays in that in-betweenness. Next, we examine the communicative activity interlocutors conduct in this space through the concept of dialogue. Our perspective on dialogue is informed by dialogism scholarship and focuses on the ethical relationship and transformative dialectic between self and the other, thus distinguished from traditions of communication analysis that foreground interlocutors' verbal/non-verbal expression and exchange of messages during interaction. Following that, we explore the complexities in the in-between space of dialogue through interpreting seven students' reported experiences of group-based intercultural learning. Based on this analysis, we argue that despite common recognition of the benefits of intercultural dialogue, an important step to explore its possibilities may be to conceive it as but one form of communication occurring in a third space, inherent in the character of social life but neither possible nor desired in all circumstances. Particularly, we discuss how intercultural education may facilitate exploration of dialogue occurring in that space, while also considering some ramifications of the concerns we raise.

\section{The in-between space of intercultural communication}

When re-evaluating central analytic concepts in anthropology, Gupta and Ferguson (1992) argue that space, culture, and people are often essentialistically mapped together through a premise that spaces are naturally disconnected. Drawing on postmodern perspectives of postcoloniality and deterritorialisation, they suggest alternative conceptualising of spaces as 'always $[\ldots]$ hierarchically interconnected' (p.8) and characterised by a 'differenceproducing set of relations' (p.16), whereby cultural difference is not considered a 'starting 
point' with a pre-existing ontological state, but an 'end product' constructed through historical processes.

This move away from 'naturalised conceptions of spatialised cultures' (p.16) towards 'interstitial zones' of deterritorialisation (p.18) resonates in theoretical developments across various social sciences, particularly in texts exploring the concept of third space, for example, Third Space in postcolonial cultural studies (Bhabha, 1994), Thirdspace in critical cultural geography (Soja, 1996), and third place/culture in language education (Kramsch, 1993). These theories share a critical stance towards essentialist binary oppositions, drawing attention to a symbolic in-between space, enabled through cultural difference and offering generative potential beyond the 'either/or' limits of dualities.

In language and intercultural communication research, in-betweenness is often presented as a 'middle' state, 'swinging between' distinctive cultural practices and engendering a 'both/and' type of hybridity constituted by elements of these cultures. Examples we believe are in line with this view include the concepts of 'middle landscape', 'intermediate zone of mediation', and multi-, pluri-, and poly- prefixes for describing a (default or desired) pre-condition for intercultural (language) education (Kramsch, 1993; Gutiérrez, Baquedano-López, \& Tejeda, 1999; Dobinson, 2014; Feng, 2009). Yet, resonant with Holliday's (2011) association with neo-essentialism of this common use of third space, we contend that though explicitly avoiding binary concepts as organising categories, this conception of in-betweenness rests upon 'a dialectical synthesis [...] predicated on the completeness and temporal sequencing of thesis/antithesis/synthesis' (Soja, 1996, pp.60-61) and takes spaces delimited by juxtaposed cultures as its starting point, thereby maintaining an essentialist position that many third space theorists challenge assertively. Moreover, such a perspective renders in-betweenness and hybridity a 'marked' phenomenon, exclusively 
relevant for individuals traversing divisive 'intercultural lines' (Holliday, 2011), such as through international business, academic sojourns, and immigration.

Comparatively, Homi Bhabha - from whose work we can trace the origin of many contemporary references to the third space concept - emphasises in-betweenness through a semiotic point of entry into an ambivalent process of 'cultural enunciation':

The pact of interpretation is never simply an act of communication between the I and the You designated in the statement. The production of meaning requires that these two places be mobilized in the passage through a Third Space, which represents both the general conditions of language and the specific implication of the utterance in a performative and institutional strategy of which it cannot 'in itself' be conscious. (Bhabha, 1994, p.36)

Placed at the two ends of the in-between space are the speaking subjects, whose communicative activity is irreducible to transparent exchange or memetic iteration of pregiven cultural contents (Bhabha, 1994, p.53). Rather, the communication is conceived of as a process of 'cultural performance' and 'strategies of discourse' (p.53), in which the speaking subjects appropriate and (re-)historicise cultural tradition - via 'statements of culture or on culture' (p.50) - to signify the 'new cultural demands, meanings, strategies in the political present' (p.51). In this way, Bhabha dissociates cultural difference from 'primordial unity or fixity’ (p.55) - a premise engendering liberal notions of multiculturalism and cultural diversity (p.50) - and locates it instead in a Third Space of enunciation characterised by 'occult instability' (p.52) and 'ambivalence in the act of interpretation' (p.53). For Bhabha, this instability and ambivalence - what he calls hybridity - is inherent in all forms of culture and has productive capacities for powerful cultural changes (p.56), for it 'displaces the histories that constitute it, and sets up new structure of authority' beyond 'received wisdom' (Rutherford, 1990, p.211). Here, hybridity gives rise to an 'other' position in the spirit of alterity (p.209), exhibiting aspects akin to those already known, but also ones strikingly 
foreign to existing frames of understanding, thus indicating a 'neither/nor' state (Bhabha, 1994, p.37). This view is clearly echoed in Soja's (1996) concept of 'thirding-as-Othering':

Each thirding $[\ldots]$ is thus an 'approximation' that builds cumulatively on earlier approximations $[\ldots]$ The critique is not meant to stop at three, to construct a holy trinity, but to build further, to move on, to continuously expand the production of knowledge beyond what is presently known. (Soja, 1996, p.61)

Intercultural communication studies have shown various links to this third space perspective on cultural difference, through an increasing interest in emergent cultural meaning as produced through interpersonal interaction rather than rooted in essentialist structural categories. Particularly, we find connections in Holliday's small culture framework, although in his earlier work he distanced his theorisation from the third space concept due to concerns with the instrumental educational aspects of its common usage (but see his more recent view in Holliday, 2018). The small culture framework examines the 'intermediate level of social structuring' where identifiable discourses or cohesive behaviour emerge among small social groupings (Holliday, 2014, p.43). A key concept in this framework is 'universal discoursal strategies', which provide 'the basic cultural competence [...] to transcend (essentialist) cultural lines' (p.45). Following Holliday's (2013) view that 'small culture formation happens all the time and is a basic essence of being human' (p.3), we may speculate that individuals' engagement with the third space is naturally inherent in all communication. Comparatively, we find that intercultural communication studies explicitly employing the third space concept often reserve it to indicate a special state of interculturality, enabled with specific conditions and attained through educated effort, sometimes involving 'AHA!' moments of epiphany (e.g. Burnapp, 2006; Dobinson, 2014; Kelly, 2009; Kramsch, 1993).

An important dimension of third space theories, as mentioned earlier, is that the 'meeting' of speaking subjects is always considered political, a theme particularly prominent 
in Bhabha's (1994) inter-group analysis of the subaltern's voice vis-à-vis hegemonic colonial narratives. From this, we may draw an analogy with micro-level interpersonal interaction, where interlocutors, with different needs, interests, and priorities at stake, 'struggle for the power to acquire and impose knowledge' (Kramsch \& Uryu, 2014, p.218). In intercultural communication research, until fairly recently (e.g. Gorski, 2008; Dervin, Gajardo, \& Lavanchy, 2011; Hoskins \& Sallah, 2011; Holliday, 2013; Ferri, 2014; Nakayama \& Martin, 2014; Phipps, 2014), this power dimension has rarely been the core of investigation.

\section{Intercultural communication as dialogue}

In language and intercultural communication studies, the last decade has seen a surge of interest in 'intercultural dialogue', propelled by intergovernmental organisations' promotion of this concept in policy documents for enhancing 'culturally diverse' living (e.g. Council of Europe, 2008; UNESCO, 2002). Theoretical and pedagogic attempts are made to understand how 'intercultural dialogue' can be facilitated (e.g. Bergan \& van’t Land, 2010; Haydari \& Holmes, 2015; Houghton, 2012). Here, 'intercultural dialogue' is mostly considered desirable verbal interaction, conducted through good will as well as tolerance and believed to promote understanding conductive to harmonious co-existence (Phipps, 2014). However, critics are sceptical of the assumedly positive results (e.g. Dervin, Fajardo, \& Lavanchy, 2011), providing examples that 'intercultural dialogue' may collapse, intensify divisions, and reinforce social inequity (Gunn, 2015; Phipps, 2014; Riitaoja \& Dervin, 2014). They suggest that common usage of 'intercultural dialogue' can assume a utopian character and thus call for more sophisticated analysis.

MacDonald and O’Regan (2013) and Ferri (2016) (drawing on the work of e.g. Derrida, Levinas) propose more considered frameworks for dialogue by alerting the field to the ethical relation between self and the other. Here, dialogue is theorised in relation to an 
'irreducible distance and separation between the self and other' (MacDonald \&O'Regan, 2013, p.1016) and posited as an intercultural responsibility for the other realised through 'ever-receding, deferred understanding' (Ferri, 2016, p.102). This involves discovering the existential state of self and the other both as 'incomplete beings' responding to uncertainty in the material presence of the other. Such a process can be traumatic, involving 'the aspect of refusal of engagement, of fear, or of misunderstanding' (p.115). This view brings to surface the premise implicit in popular usage of 'intercultural dialogue', which construes dialogue as a transparent verbal exchange conducted between individuals anchored to distinctive social entities, and a pathway to a 'complete' intercultural state, such as the achievement of 'common ground'.

Observations of the theoretical weakness of 'intercultural dialogue' in the form circulated in many research texts and policy documents resonates with critical discussions of dialogue in communication studies. Deetz and Simpson (2004) note that dialogue is used as 'a common catch-phrase for many forms of discourse' (p.152). They particularly problematise a native 'coming-together' approach to dialogue, considering it 'one of the greatest threats' to productive dialogue due to its conceptual bias towards individuals as the originators of meaning and their 'successful' expression of internally located meanings as $a$ priori determinants of knowledge (p.152). Drawing on Gadamer and Habermas, they argue that in productive dialogue, the basis for 'voice' should be an openly formed agreement, where interlocutors commit to a process of self-destruction and open up 'to the indeterminacy' of otherness (p.143). Resonantly, Baxter (2004) contends that in dialogue, bipolar forces such as certain-uncertainty and 'expression-nonexpression' 'do not exist in parallel to one another but interweave in ongoing dialectical interplay' (p.115).

In this scholarship, dialogue is conceived of as a relational process that enables growth through transforming perspectives rather than achieving 'mutual understanding'. The 
argument then follows that intercultural dialogue should destabilise communication from preoccupations with fixity to the processes interdependently constructed by interlocutors (e.g. Dervin, 2016; Ferri, 2016).

We are, however, reminded that dialogue is but one specific mode of communication. Some argue that it is naturally 'inherent in the character of all social life' (Wood, 2004, p.xx), even though it may be ephemeral in operation (Deetz \& Simpson, 2004). Also, in certain contexts, non-dialogic modes of conversation may have greater rhetorical potential to empower marginalised voices (Wood, 2004). It is noted that 'life presents many situations that do not demand dialogic responses' (Anderson, Baxter \& Cissna, 2004, p.15) and, even when desired, dialogue is not always possible in the context of unequal power relations (Wood, 2004).

\section{Thirdness in the intercultural space of dialogue}

While critical scholarship on dialogue has focused on self-other relation, and third space theories on cultural production, we see them conceptually intersecting at a politicallycharged, yet enabling, in-between space, constructed by interlocutors and characterised by open-ended verbal interchange. Central to both domains of scholarship is a poststructuralist position seeking to induce - rather than tame - difference for new meanings to emerge. In this in-between space, an ambivalent and hybrid process of meaning negotiation - what we call thirdness in this paper - is privileged, characterised by indeterminacy rather than fixity, multivocality rather than totalising unity, the production of other ground rather than reproductive self-expression oriented to common or middle ground. Furthermore, scholarships in both domains (or their interpretations in the field of intercultural communication) question whether their key concepts, i.e. dialogue and third space, should concern phenomena naturally inherent in social life or those exclusive to educated modes of 
living that individuals should be 'elevated' to. Enriched by this common concern as well as their respective foci on self-other relation and cultural production, we consider the conceptual intersection between the two domains identified above a revealing location for theorising intercultural communication as dialogue, or intercultural dialogue.

We suggest that meaningful intercultural dialogue requires a political sensitivity and ethical responsiveness to the thirdness in the in-between space of communication. In other words, for an intercultural space of dialogue to open up, interlocutors need to engage with the thirdness in their communicative processes and '[willingly] descend into that alien territory' of 'occult instability' (Bhabha, 1994, p.56). This involves transcending the limits of fixityoriented approaches to communication by questioning received ideas about self, other, and culture, and rethinking self-other relation through difference as a political product of dynamic cultural performance and enunciation. In the absence of such sensitivity and responsiveness, as in a 'native' talk-and-talk approach to dialogue that privileges self-expression, it is likely that 'voices' will repeat the status quo, opportunities of discovering new meaning are precluded, and the transformative potential afforded by the thirdness in the "normal locale of postmodern subjects' (Gupta and Ferguson, 1992, p.18) remain obscure.

\section{The study}

We now turn to describe the study and the data we draw upon. The data are selected from students' reflective essays about their group work experiences on an 'intercultural competence' module. In groups of four or five, students completed two group projects over 8 weeks: a report on 'how to manage an emerging culturally diverse workplace' to an imagined company expanding overseas, and a one-hour-long intercultural training session to guest 'trainees' from the real world. Also, each student wrote in situ 'learning journals', recording 'moments of significance' identified from their group work. For the final assessment, 
students drew on these journals to write post hoc reflections in an essay form on their personalised trajectories of 'intercultural competence development'.

These essays were produced by discrete individuals, thus foregrounding 'one-sided' reflections rather than multiple accounts from interacting interlocutors (cf. 'Interaction Process Analysis' in Foot, 1982). Nevertheless, with their highly reflective nature induced by events of group interaction, we believe that these essays provided meaningful windows into intercultural dialogue when conceived in terms of one's ethical responses to the other and the concomitant transformative processes of self.

We gained ethical approval from 14 students (from a possible 91 who had completed their degrees over a four-year period) to use their essays for research purposes. Although we cannot, and do not wish to, claim that these 14 are representative of the full corpus in detail, they illustrate the many common stories told and the variety of experiences. With these essays, we intended to explore how students' reflections on their self-other interchange potentially reveal their dialogic engagement with thirdness in relation to three broad questions:

(1) How did students construct difference and power dynamics in their in-between space of communication?

(2) Were there discernible dialogic moments in the students' reflections? If so, how were they induced and what were the outcomes?

(3) Were there alternative modes of conversation present in the reported interchanges? If so, how were they related to the dialogic moments?

Given that the essays were originally written for an academic assignment and thus shaped by the specific module aims and objectives, it was necessary for us to engage with this data selectively for our purposes in this paper. We aimed to reach data saturation via richness 
rather than thickness (Fusch \& Mess, 2015) by isolating examples from the data sufficient for analysis on the above questions. Therefore, we focused on 7 of the 14 essays (pseudonyms adopted) we considered particularly rich in reflective commentaries about self and interchange where self felt confronted by an other. In keeping with this focus, we used a thematic method (Ritchie et al., 2013) to further select and interpret relevant segments of content, particularly attending to students' statements about their own values, inner thoughts and doubts, their tentative, definitive, and/or evaluative comments on the other, and their accounts of experiences with the other that disturbed their comfort zones. In our interpretation, we also drew on discourse analysis (Fairclough, 2013), where relevant, for finer examination of how students constructed understandings and conveyed subtle meanings through the use of specific words.

In the following, we discuss three main themes emerging from this exploration and use selected extracts to portray an ever-shifting communicative space, where the students dipped in and out of received notions on difference and power and dialogical relations with the other. After each extract, we indicate its source through codes such as 'Finley-PH' or 'Elisa-IS-W4', referring to the student's pseudonym, the post hoc or in situ status of their reflection, and the week number during their group projects (where applicable).

\section{Construction of difference: preformed selves and performed selves}

All students commented on the key differences they perceived in their 'intercultural' groups. Notably, most avoided national-cultural categories, e.g. 'I realised that we all have a different work attitude' (Logan-PH), '[there are] different heads and thoughts and personalities and experiences' (Casey-IS-W1), and 'the strongest "cultural differences" came through as differences in working style and work ethic [...] not necessarily stem from different cultural backgrounds but rather from different personalities' (Alex-PH). This suggests that students' 
positioning of their interpretive lens went against a stereotyping discourse typically associated with social groups at national and ethnic levels - arguably a response to the critique of cultural essentialism conducted in their class discussions.

Nevertheless, with the emphasis shifted from the sociocultural to the personal, the inbetween spaces still tended to be seen as constituted by preformed selves, 'knowable' and 'predictable' with some certainty. For example, Alex defined her 'work style' against an 'other', writing that 'I know for myself, I could not work like that, I would get a heart attack because I would be so stressed' (Alex-IS-W4). Interestingly, Jamie presented a 'paradox' between difference and 'sameness' when explaining the uncomfortable tension with an 'other': 'member A's personality and mine are too similar to work properly together; we both like leading and monitoring every move' (Jamie-PH). Arguably, the 'sameness' noted in personality, as part of two preformed selves, blurred recognition, or blocked articulation, of difference operating at other levels as the deeper reason for tension.

On two occasions, however, students questioned whether observed behaviour was indeed a manifestation of pre-existing qualities. As Elisa wrote: 'I am not sure if what happened can be considered a cultural trait or a personal one. But does it matter?' (Elisa-ISW3). Finley's reflection on 'change' interrogated fixity more explicitly:

Our awareness of different priorities may add/change our understanding of our priorities or at least understand others' behaviours and attitudes depending on their priorities $[\ldots]$ Talking about personal life, responsibilities and priorities, I learnt that these sometimes might be changeable depending on $[\ldots]$ situations. I believe $[\ldots]$ each person has some stable beliefs and values and some are more like fluid and mobile. (Finley-PH)

Further questioning of pre-existing difference was evident in some students' comments on self and other as being relationally constructed. For instance, Casey 'learnt from previous experiences of team work that [...] I might sound a little bit arrogant when I get overexcited about something', thus trying 'my hardest to find a way to convey my ideas without being too 
"dictatorial"" (Casey-IS-W1). To perform the self in relation to the (anticipated) responses of the 'other' is also reflected in concerns at being pre-determined by the 'other' through stable entities. In a group meeting, Elisa was late by twenty minutes, but no one 'seemed annoyed'. She felt 'a relief because I do not like to be perceived as the typical Italian late person' (ElisaIS-W1). Finley wrote about an inner 'debate' regarding whether she should understand her group members by starting with stereotypes or observation. When she turned to herself, she commented emphatically:

I was worried about how people see me!! How people stereotype me!!! How people understand me!! How people judge on each other!!! How I have to act and react in different situations! Do we respond as we are or as their expectations? So I decided to be myself, and try to understand their expectations. I tried to be well organised and work hard [...] this might be because I am aware of stereotyping and I was afraid of it. (FinleyIS-W1)

Thus, the students all articulated stances which avoided essentialism especially at 'large culture' (Holliday, 1999) levels, albeit moving between hardened and fluid states of identity. When shifting to identity categories at smaller levels, they seemed holding on to preformed selves, awaiting moments for these to 'get revealed' (Baxter, 2004, p.110); at other times, they allowed (at least their own) selves to be 'defined, or authored, in the interaction between the relationship parties' (Baxter, 2004, p.110). In the latter case, we would argue, they recognise interlocutors' performativity and 'cracked open' the totalising closure towards 'all permanent constructions' (Soja, 1996, p.60), thereby demonstrating closer engagement with the thirdness of their communicative space. 


\title{
Contestation of power: authority and resistance
}

Most students described their group relations as 'hierarchical', explaining how some members 'came into power' by asserting leadership and others came to 'accept' their 'subordinate' positions:

\begin{abstract}
We discussed a lot but nobody was ready to take a decision [...] I realised that it was mainly my need to be very organised. In addition we all had other coursework and it was my aim to be able to plan my and our group work in consideration of all the deadlines [...]. My frustration and need for structure drove me to take over the lead role. (Alex-
\end{abstract} $\mathrm{PH})$

I kind of went into the role of the group leader [...] I am worried about the impression others have about me. My intent is rather starting a discussion about the different possibilities rather than deciding and I am not proud of this position [...] But at some point, someone needs to step up and make a decision to keep the work effectively. (Logan-IS-W3)

In the above, both Alex and Logan felt involuntarily 'driven' into positions of power by the others. Here then, power distribution, starting with the emergence of leadership, was related to the workplace demands (e.g. task effectiveness, time management, and workload pressure) associated with the group projects as assessed tasks, demands arguably connected with neoliberal imperatives higher education is wrestling with, in particular the 'responsibilisation' of individuals for their own progress and achievements (Olsen \& Peters, 2005). As the students commented, 'you pay to go to a university; students mostly focus on their personal success' (Alex-IS-W1); 'it is a grade we are getting within our programme we are paying for and in the country where I am from, it does count a lot' (Logan-IS-W5). Thus, though aware of the ultimate aims of intercultural learning, students were equally conscious of their need to satisfy the more immediate task demands through interdependence, thus developing a 'bias toward making decisions' typical of organisational communication (Deetz \& Simpson, 2004, 
p.149). Leadership was then deemed 'necessary' and 'naturally assigned' to individuals whose task-focused interests were most assertively or convincingly expressed.

However, by constructing leadership roles as strategic (re)actions, Alex and Logan also perceived their 'power' as a danger to their intercultural interaction with group members. This is reflected in their sensitivity towards 'equality', e.g. 'taking the lead [...] but offering my ideas with good intent and not in a condescending way' (Alex-IS-W8) and 'always ask[ing] all members if they are fine with my suggestion without urging anyone because everyone is an equal member' (Logan-IS-W2). Nevertheless, such an (arguably) a-political approach to maintaining equality, perceived through strategic necessity and supported by 'warm, caring attitudes and open acceptance' may cover up 'asymmetries of concern [...] deeply embedded in socially formed experiences' (Deetz \& Simpson, 2004, p.149).

Indeed, as the group work progressed, students' accounts of specific encounters assumed increasingly political tones. Power was used not only to facilitate, but also to enforce, decision-making. This was sometimes presented as a group 'compromise' - or a 'common ground' - where the voices of a few were privileged over others:

We really need to find a compromise [...] which, I think we found, as we will meet again in two weeks and until then we should have [a] raw version of the report. Well, I actually demanded it [...] I just feel that things need to be defined. (Alex-IS-W4)

A [our 'leader'] decided to change most of what was written by [C and D] because s/he felt it was not good for our standards [...]. I indeed agreed with A and so did B. A brought up the 'writing style issue' [to $\mathrm{C}$ and $\mathrm{D}$ in our meeting]. [... $\mathrm{C}$ said 'I know it is not good, I cannot write well as you do, please change everything, I'm ok with it'. (ElisaIS-W4)

Yet, concerns were expressed by those perceived at the bottom end of the hierarchy. Jamie represented her group relation as a power struggle from the outset, describing how Member A 'won this "game" of leadership and control' (Jamie-PH) while she herself 'compromised' to a 
'subordinate' position under the pressure of 'consensus' from the majority. Similarly, Amy recognised the power asymmetries in her group and questioned the legitimacy of the authority assumed by the 'leader':

I feel Member A began to play the role of team leader [...] I realised that the rest of us all kind of 'respect' her role [...] even normally when A presented some ideas, no one disagree, she has authority [...] Although I can understand A did this because she really wants us [to] have a good mark but who does not? [...] She may thought she is the best[,] but I am also confident in my ability and want to do something, although I am not good at academic writing I am confident in my ideas. (Amy-PH)

Along with the comments on power imbalance emerged an 'us/them' discourse acknowledging individuals' positions in the hierarchy. In the above, Amy used '(the rest of) us' to articulate her inner resistance to the 'leader' through constructing her as an 'other' standing against 'a subordinate majority'. For Jamie, a similar 'other' in her group discursively dominated the majority, as "finally "we", meaning member A, decided to come up with ideally every content concerning the report' (Jamie-IS-W4).

Interestingly, for Elisa, the 'unwanted' power asymmetries in her group were created, almost forcefully, by a member who othered himself/herself through performing a 'subordinate' role:

Member C brought us some notes [and] said 'you can decide if either to use it or not, I am not sure it is what you want'. I felt very uncomfortable, $\mathrm{C}$ was giving us [...] the power to decide what to do with it, as this person was degrading her/himself to something like a subordinate that would not feel confident enough or in the right position to give his/her point of view [...] No one answered in any specific way to tackle what $\mathrm{s} /$ he just said, as we were agreeing to give him/her this subordinate role. I am sure we did not do it on purpose. (Elisa-IS-W3) 
Nevertheless, Elisa reflected later on how the majority of 'us' also contributed to the sustaining of power asymmetries, which eventually resulted in the 'exclusion' of that 'subordinate other':

It seemed that two smaller [sub-groups] were formed. [In] my learning journal, at the beginning 'we' was only used to mean the whole group, while in the core of the learning journal was often used to only refer to 'A, B and I' [...] Being the majority this created a focus on our ways of working. Thus, it involuntarily delineated a standardised preference of how to communicate amongst each other, how to proceed with the organisation of the work and how to assess its appropriateness, which in some ways excluded any type of diversity. (Elisa-PH)

Clearly, these power dynamics exhibit far more complexity than stable and mutuallyaccepted relations between 'dominance' and 'subordination'. On the surface, a tacit 'common ground' seemed achieved among students on power distribution, yet alluding to the political imbalance inherent in the wider educational environment where the module is situated, namely, the neo-liberalising educational system (Olsen \& Peters, 2005) and the privilege of Anglophone academic standards in classrooms operating with English as a lingua franca (British Council, 2014). These mechanisms granted 'different degrees of recognition' to students in relation to their varied 'access to linguistic, cultural, economic and other resources' (Zotzmann \& O'Regan, 2016, p. 114), therefore provisionally 'sanctioning' the groups' delegation of power for decision-making and voicing to those individuals perceived to be the better 'fit'.

Nevertheless, all parties involved in the hierarchical relations demonstrated a political sensitivity to the meaning of 'power', continually contesting it in relation to the necessity, risk, and legitimacy of decision-making authority. Underneath the surface of tacitly agreed 'common grounds', 'power' asserted itself in different forms - sometimes through 
dominance, sometimes through resistance. This dynamic 'power struggle' is captured well in the words of a 'powerless leader':

I felt pushed into several roles in our group. In the end, I could not manage to fulfil each of them and as these complex tasks were not supposed to be undertaken by one person. This is $[\ldots]$ connected to my feeling of powerlessness which I felt frequently. (LoganPH)

\section{Communication dynamics: A dialogue-monologue dialectic}

The modes of communication students adopted in approaching difference and power dynamics in their intercultural group work present much variety. We noted frequent dialogic moments in students' accounts, but these moments rarely occupied a discrete 'space', as they mostly occurred in some relation to monologue.

For example, Logan recounted how she tried to 'help' group members on the task:

I specifically invited $\mathrm{C}$ and $\mathrm{D}$ to share their thoughts with us $[\ldots]$ however, they did not do so. On the contrary, A and B became more self-confident and autonomous whereby our team work became more effective. Also, if I tried to motivate C and D by asking them directly, they did not really respond to anything. (Logan-PH)

We find emphasised here the narrator's self-expression realised through the response of the other. For Logan, two members demonstrated 'self-confidence' and 'autonomy', which were quickly 'approved' vis-à-vis the project 'success'. She placed the other two 'non-responding' members in contrast, and conveyed a note of frustration through 'however' and 'on the contrary'. What constitutes 'approved' and 'frustrating' responses seemed shaped by Logan's self-originated meanings predating the group interaction. Otherness was taken as a reflector of the self's internally located meaning, thus reflecting a conversational pattern directed by a single voice. We would relate such conversations to Buber's (1947) monologue disguised as dialogue, where 'two or more men, meeting in space, speak each with himself in strangely 
tortuous and circuitous ways and yet imagine they have escaped the torment of being thrown back on their own resources' (p.19).

Alex's account of a 'conflict' provided greater depth of illustration. On one occasion, Alex discussed the project with her group and 'tried to be nice', but was 'shouted at' by a group member ('C') and then faced 'opposing wind whenever I wanted to say something'. She wrote afterwards:

\begin{abstract}
My understanding is that ' $\mathrm{C}$ ' must have felt patronised by my behaviour which I didn't want to happen at all. I probably was very determined in my role to hold everything together, I am sorry if it came across in a patronising way. On the other hand also I see a lack of ' $\mathrm{C}$ ' questioning his/her own behaviour as well. Rather jumping to conclusions and starting to resent me. I am very open for discussion and critique but not in a rather 'immature' way, as I perceive it to be. (Alex-IS-W8)
\end{abstract}

Here, Alex responded to otherness by starting to 'think from the other's perspective' and seek alternative meaning of her own behaviour. This may be seen as a 'native' dialogic attempt following the principles of good intention, understanding, and empathy (Deetz \& Simpson, 2004). However, the words 'on the other hand' shifted the emerging window of selfdestruction quickly to self-expression. The other's behaviour was framed in concepts not sought from the outside, but derived a priori within the self. The meaning of '(im)maturity', and the concepts particularly pertinent to dialogue, including 'question(ing)', 'open', and 'critique', remained default. What transpires to us is an 'invisible discursive closure' (Deetz \& Simpson, 2004) denoting monologic communication. The 'confrontation' from the 'other' was disapproved of as a reason for difficulty, rather than responded to as the 'raw material for the production of something new' (Deetz \& Simpson, 2004).

Nevertheless, a dialogic opening seems discernible from the monologue above through Alex's acknowledgment of the importance of questioning meaning and her brief attempt to do it. This is also reflected in her use of inverted commas for the word 'immature' 
and the qualifying statements 'my understanding is that' and 'as I perceive it to be'. We find such alternation between dialogue and monologue common in all students' in situ reflections, although the dialogic parts were often momentary and usually fell back on monologic notes.

What we find equally significant is that sometimes, students conveyed a need for dialogue after experiences of tension, most directly expressed in Alex's reflections on seeking multiple voices:

I would have wished for a constructive conversation where ' $\mathrm{C}$ ' and I would have been able to describe our perspectives in a respectful way and that we would have come out of the discussion much wiser, more elevated and in agreement and with respect for the other's story. (Alex-IS-W7)

However, based on the reported experiences, such dialogical meetings rarely occurred. Even an 'exception' in Elisa's group, where an ad hoc meeting was arranged 'to finally express our thoughts about the group work' and 'could have been very beneficial', had the outcome that 'no one really gave any feedback about how they felt' and 'we only had a general chat' (Elisa-IS-W8).

Students' writings offered some clues to possible reasons for the difficulty of dialogue even when it was desired, including task pressure and individual communication preference:

We really needed to focus on finalising the draft and think only about that, since so many things for other modules needed to be done as well, I felt that thinking about any other problem within the group was not worth it. (Elisa-IS-W4)

My [personal and family] circumstances started to affect my life and studying progress [...] I completely understood their [group members'] thoughts and feelings when some of them looked angry $[\ldots]$ but it was really hard to talk and express myself and feelings [...] (Finley-IS-W4)

Aside from contextual and personal factors, which merit in-depth discussion, we however focus on a relation-oriented dimension for the main purposes of this study. Here, we draw on 
Amy's account of her last group meeting, arranged with a view to celebrating the grade they received for their project and reflecting on the entire group work:

I did not talk too much except saying really happy and thank you for everyone which is totally a lie. I just feel my responsibility for this group is totally done[.] I [am] really tired of sitting with them. (Amy-IS-W8)

Based on Amy's account, we would imagine that the group managed to maintain some harmony in their conversational flow - partly achieved through Amy's 'lie'. However, that Amy knew she was 'lying' indicates her intentional withdrawal of her voice, hence her nondialogic engagement with the meeting. The underlying reason is implied through a feeling of relief associated with task completion, which enabled her to retreat from a 'tiring' relationship with 'them' (a pattern we also noted in many other students' last in situ journal entries). Therefore, Amy's disengagement from dialogue in this particular event conveys a cumulative desire to withdraw from a possible dialogic relation with the 'other'. This desire seems intertwined with the power dynamics we discussed earlier, as some weeks prior to the last group meeting, she wrote:

Group Member C is against whatever I said in the group discussion, even did not allow me to finish my sentence [e]very time. I then realised that the other members can feel how rude $\mathrm{C}$ is to me but they just let her do it because they assumed I am useless [...] I have no choice but to think that part of the reason is I am not from European Union. (Amy-IS-W3)

They did not use those shit I wrote. I tried to control myself and stop talking during this meeting although I also did not have too much talking chances before. (Amy-IS-W4)

As shown above, the group's mode of communication seemed influenced by, and in turn sustained, an asymmetric power relation. In principle, group meetings were organised as a mutually agreed forum for verbal exchange of ideas. What seemed practised instead is that some voices continually dominated the conversations, while others silenced. There seems an 
absence of dialogically-induced transformation mutually recognised by the group members, for example, regarding perspectives on, and ways of addressing, difference and exclusion. The group relation seemed sustained in monologue, which led Amy to eventually appropriate (somewhat knowingly) the EU/non-EU divide to (re)produce essentialist cultural difference to deal with - or live with - the political present of her group. This monologic relationship culminated in verbal interactions where words were uttered to fulfil conversational functions by way of closing dialogue.

Yet, as mentioned earlier, notable moments occurred where students demonstrated dialogic engagement through turning to the other and, as a result, re-thinking self. These moments are particularly evident in reflections carried out some time after their group task completion. For example: '[rather than] just became angry and frustrated [with C], I could have asked her what her motivation was and what she needed in that situation to make it work' (Alex-PH); '[our] reaction was simply to rewrite anything that $\mathrm{C}$ and $\mathrm{D}$ wrote $[\ldots]$ instead of engaging in a conversation that would have helped everyone' (Elisa-PH); 'I realised [...] I have been always avoiding conflict [...] something [that] never occurred to my mind before' (Amy-PH).

Such renewed understandings about self and (alternative approaches to) tension were on one occasion accompanied by the comment that 'I don't know if I am more open-minded but $[\ldots]$ I felt content that I went through that path because now I feel more mature' (Jamie$\mathrm{PH})$. These suggest to us that students were questioning fixity-oriented understandings and were able to see their selves in terms of continual, incomplete formation through the pull from the 'other'. Although these moments most obviously occurred as individual introspection after the group relations ended, they indicate students' post hoc engagement with 'dialogue - no matter whether spoken or silent' (Buber, 1947, p.19), thus providing hope for establishing constructive conditions for future intercultural dialogue. 


\section{Discussion and conclusion}

In this paper, we explored some of the complexities in the in-between space of intercultural dialogue through our students' reported experiences of group-based intercultural learning. What emerged to us is less about an intercultural 'dialogic relation between geographically distinct societies' (Gupta \& Ferguson, 1992, p.14) than about a dialogue-monologue dialectic in which the students constantly negotiated the meaning of cultural difference and power relations. In this section, we discuss the difficulty and hope of intercultural dialogue (regarding both its praxis and pedagogy) revealed by this dialectic and explore how these may be understood from a third space perspective, based on which we propose a potential reconceptualisation of intercultural dialogue.

As our analysis shows, the students dipped in and out of dialogical relationships: sometimes verbally initiating dialogue with the 'other'; sometimes deciding to consciously engage in monologue (disguised as dialogue) through transmission of internally located meaning originated by preformed selves; at other times engaging introspectively in dialogue through realising in their post hoc writings that they had practised monologue in the moment of interaction and thus opening up to self-questioning towards alternative perspectives. Such observations gave us some optimism that the module's aims towards intercultural learning may have played a role in facilitating students' dialogic praxis towards self transformation.

Nevertheless, our analysis does not lead us to a teleological understanding of the effect of our educational intervention. We cannot bypass the observation that despite recognising their group 'success' based on the grades they received for their 'intercultural' projects, most of these students 'celebrated' the termination of their group relations with signs of relief, sometimes even concluding on the 'failure of the group work' in terms of their 'management of cultural diversity'. The dialogic moments we were able to capture from the data were often accompanied by expressions of fatigue, frustration, or regret, while we noted 
monologic relations sometimes developing through 'harmonious' group interaction maintained through 'lies' and acquiescence in power imbalance.

At one level, these paradoxical and somewhat unsettling observations point to the problems with common conceptions of intercultural dialogue, which often subscribe to a discourse of 'harmonious (co-)existence' as a projected endpoint of intercultural communication (MacDonald \& O’Regan, 2013). According to MacDonald \& O'Regan (2013), such a discourse misleads interlocutors towards a moral imperative of tolerance, encouraging the entertaining of the acts of the other under sufferance and subjecting their acts to 'a privileged hegemonic order of the self' (p.1016). As such, the obligation to act 'interculturally' through tolerance emphasises closure rather than openness, which, as illustrated in our data, may result in 'ethical paralysis and inertia' (p.1010) and render dialogue neither possible nor desirable.

And yet, at another level, our analysis points to the students' struggles in meaning articulation as a possible birthplace of their dialogic openings. The students rejected overt essentialist assertions and demonstrated some discursive attempts to contest the meaning of difference and power. These processes - occurring against competing individual priorities burdened by external demands and group hierarchies mirroring larger power asymmetries presaged a 'split-space of enunciation' (Bhabha, 1994, p.56). The students' responses to the tensions in that split-space and their struggles for voicing therein (e.g. dipping in and out of roles of power and subordination) sometimes opened the way to perspective transformation, sometimes brought about feelings of powerlessness and exclusion, leading them to nondialogic communication through the (re)production of a priori cultural difference and performance on the 'common ground'.

These processes were not planned in the module aims but, rather, seem organically induced by the tensions occurring in the students' self-other encounters. Thus, with a certain 
intercultural stimulus from our educational intervention, we would argue that the students naturally found themselves in an ambivalent third space and 'descend[ed] into that alien territory' of 'occult instability' (Bhabha, 1994, p.56) to make meaning of tension and explore the possibility for constructive change through their dialogic efforts. Viewed from this perspective, the hope for intercultural dialogue lies less in the teleological possibilities of creating dialogue (e.g. intercultural training - in the form of lecture, experiential activity, reflective writing exercise etc. - aimed at fostering attitudes and competencies to reconcile cultural difference) than in the ways interlocutors engage with the thirdness in their communicative processes to establish productive conditions for sustaining dialogue.

This study has thus drawn us to conceive of intercultural communication as inherently a dialogic response to the thirdness in the 'normal locale of postmodern subjects' (Gupta and Ferguson, 1992, p.18), a process enabled through a natural human capacity to engage with difference and understand tension, which can be facilitated by education in certain ways. Alongside a possible ethical inertia arising from the moral imperative of intercultural tolerance (MacDonald \& O’Regan, 2013), this third space perspective not only takes intercultural communication beyond discourses of cultural diversity and harmony, but also adds to our understandings of why productive dialogue towards 'other ground' is often difficult to achieve and sometimes non-dialogic modes of communication may be employed as an intentional strategy in power struggles.

The findings raised several concerns for us both as authors and intercultural educators, regarding whether we should and how we can: a) support our students (and the wider community) to engage with intercultural dialogue by exploring the potential in that split-space of enunciation; b) present intercultural communication as an open-ended process of self transformation situated in an ever-shifting, politically-charged third space; and c) highlight that rather than creating ideal resolution, intercultural encounters often result in 
withdrawal from dialogue, while productive dialogic spaces may open up (even momentarily or unspokenly) through tense, sometimes highly distressing, power struggles (cf. McKinley, Dunworth, Grimshaw \& Iwaniec in this issue).

We believe that raising such concerns leads individuals to a fuller preparation for the eventualities of thirdness, through consideration of the limitations, and 'sugar-coated' nature, of ideal definitions of intercultural communication and intercultural dialogue. Specifically, in higher education, this entails not only sensitising students to relevant concepts, but also exposing them to situations where they engage with the praxis of dialogue vis-à-vis power struggles. We suspect that the ramifications of knowingly doing this could encompass ethical concerns and challenges from neoliberal forces, which load higher education with pressures from marketing, ranking, and satisfaction surveys (see recent LAIC discussions on education and neoliberalism in Collins, 2018 and Gray, O’Regan, \& Wallace, 2018). Nevertheless, we contend that ultimately, the complexities that individuals may encounter, the resulting impact on their approaches to dialogue, and the transformative potential of intercultural communication as dialogue, as our data has shown us here, should be presented and discussed.

In conclusion, we urge that intercultural dialogue be distinguished from a native 'talkand-talk' mode of intercultural communication that is rooted in a normalising 'cultural diversity' discourse and privileges spoken forms of interpersonal communication and selfexpression. Particular attention should be paid to situations where such a monologic approach to intercultural communication blocks dialogue and serves to implicitly endorse hegemonic discourses. Additionally, we need to distance away from a faith in dialogue as a teleologically-achievable ideal, a faith that may be easily cultivated through slogan but, equally, quickly lost in the wake of unsettling events associated with varying forms of division and injustice. Instead, we call for theoretical recognition of intercultural dialogue as 
a political and ethical response to the thirdness in the in-between space of communication. Borrowing Wood's (2004) words, we propose that as a conceptual step in exploring the possibilities of intercultural dialogue, it may be less productive to 'produce principles for improving communication' (p. xxiii) towards dialogue in a third space as an elevated state of 'completeness', than to knowingly engage with dialogue and thirdness 'as an inherent, inescapable, and pervasive feature of all social life and interaction'. 


\section{References}

Baxter, L. A. (2004). Dialogues of relating. In R. Anderson, L. A. Baxter, \& K. N. Cissna (Eds.), Dialogue: Theorising difference in communication studies (pp. 107-124). Thousand Oaks, CA: Sage.

Bergan, S., \& van't Land, H. (Eds.) Speaking across borders. The role of higher education in furthering intercultural dialogue. Strasbourg: Council of Europe Publishing.

Bhabha, H. K. (1994). The location of culture. London: Routledge.

British Council. (2014). English as a medium of instruction - a growing global phenomenon. Retrieved from https://www.britishcouncil.org/sites/default/files/e484_emi__cover_option_3_final_web.pdf

Buber, M. (1947). Between man and man. (R. G. Smith, Trans.). London: Kegan Paul.

Burnapp, D. (2006). Trajectories of adjustment of international students: U-curve, learning curve, or Third Space. Intercultural Education, 17(1), 81-93.

Byram, M. (2003). On being 'bicultural' and 'intercultural'. In G. Alred, M. Byram, \& M. Fleming (Eds.), Intercultural Experience and Education (pp. 50-66). Clevedon: Multilingual Matters.

Collins, H. (2018). Interculturality from above and below: Navigating uneven discourses in a neoliberal university system. Language and Intercultural Communication, 18(2), 167183.

Council of Europe. (2008). Living together as equals in dignity. White paper on intercultural dialogue. Retrieved from www.coe.int/t/dg4/intercultural/WhitePaper_InterculturalDIalogue_2_en.asp\#

Deardorff, D. K. (2006). The Sage handbook of intercultural competence. London: Sage.

Deetz, S., \& Simpson, J. (2004). Critical organisational dialogue: Open formation and demand of 'otherness'. In R. Anderson, L. A. Baxter, \& K. N. Cissa (Eds.), Dialogue: Theorising difference in communication studies (pp. 141-158). Thousand Oaks, CA: Sage.

Dervin, F. (2016). Interculturality in Education: A theoretical and methodological toolbox. Basingstoke: Palgrave Macmillan.

Dervin, F., Gajardo, A., \& Lavanchy, A. (Eds.) (2011). Politics of interculturality. Newcastle upon Tyne: Cambridge Scholars Publishing. 
Dobinson, T. (2014). Occupying the 'Third Space': Perspectives and experiences of Asian English language teachers. In K. Dunworth, \& G. Zhang (Eds.). Critical Perspectives on Language Education (pp. 9-27). London: Springer.

Fairclough, N. (2013). Critical discourse analysis: The critical study of language. London: Routledge.

Feng, A. (2009). Becoming interculturally competent in a third space. In A. Feng, M. Byram, \& M. Fleming (Eds.), Becoming interculturally competent through education and training (pp.71-91). Bristol: Multilingual Matters.

Ferri, G. (2014). Ethical communication and intercultural responsibility: A philosophical perspective. Language and Intercultural Communication, 14(1), 7-23.

Ferri, G. (2016). Intercultural competence and the promise of understanding. In F. Dervin \& Z. Gross (Eds.), Intercultural competence in education: Alternative approaches to different times (pp. 97-120). Basingstoke: Palgrave Macmillan.

Foot, H. (1982). Interactional analysis: The observation of individuals in a group setting. In G. M. Breakwell, H. Foot, \& R. Gilmour (Eds.), Social psychology: A practical manual (pp. 57-74). London: Palgrave Macmillan.

Fusch, P. I., \& Ness, L. R. (2015). Are we there yet? Data saturation in qualitative research. The qualitative report, 20(9), 1408-1416.

Gray, J., O’Regan, J. P., \& Wallace, C. (2018). Education and the discourse of global neoliberalism. Special issue for Language and Intercultural Communication, 18(5).

Gonçalves, S. (2011). Intangible culture, cooperation and intercultural dialogue among university students. Intercultural Education, 22(1), 83-95.

Gorski, P. C. (2008). Good intentions are not enough: A decolonising intercultural education. Intercultural Education, 19(6), 515-525.

Gutiérrez, K. D., Baquedano-López, P., \& Tejeda, C. (1999). Rethinking diversity: Hybridity and hybrid language practices in the third space. Mind, Culture, and Activity, 6(4), 286-303.

Gunn, D. (2015). Storms, lies, and silence: Notes towards a non-dialogic mode of intercultural contact. In N. Haydari \& P. Holmes (Eds.), Case studies in intercultural dialogue (pp.131-143). Dubuque: Kendall Hunt Publishing Company.

Gupta, A., \& Ferguson, J. (1992). Beyond 'culture': Space, identity, and the politics of difference. Cultural Anthropology, 7(1), 6-23.

Haydari, N., \& Holmes, P. (Eds.) (2015). Case studies in intercultural dialogue. Dubuque: Kendall Hunt Publishing Company. 
Holliday, A. (1999). Small cultures. Applied Linguistics, 20(2), 237-264.

Holliday, A. (2011). Intercultural communication and ideology. London: Sage.

Holliday, A. (2013). Understanding intercultural communication: Negotiating a grammar of culture ( $1^{\text {st }}$ ed.). London: Routledge.

Holliday, A. (2014). Culture, communication, context and power. In J. Jackson (Ed.), The Routledge handbook of language and intercultural communication (pp. 3751). Abingdon: Routledge.

Holliday, A. (2019). Understanding intercultural communication: Negotiating a grammar of culture (2 $2^{\text {nd }}$ ed.). New York: Routledge.

Houghton, S. A. (Ed.) (2012). Intercultural dialogue in practice: Managing value judgement in foreign language education. Bristol: Multilingual Matters.

Hoskins, B. \& Sallah, M. (2011). Developing intercultural competence in Europe: The challenges. Language and Intercultural Communication, 11(2), 113-125.

MacDonald, M. N., \& O’Regan, J. P. (2013). The ethics of intercultural communication. Educational Philosophy and Theory, 45(10), 1005-1017.

Nakayama, T. K., \& Martin, J. N. (2014). Ethical issues in intercultural communication competence. In, X. Dai, \& G. Chen. (Eds.). Intercultural communication competence: Conceptualisation and its development in cultural contexts and interactions (pp.97117). Newcastle upon Tyne: Cambridge Scholars Publishing.

Olssen, M., \& Peters, M. A. (2005). Neoliberalism, higher education and the knowledge economy: From the free market to knowledge capitalism. Journal of education policy, 20(3), 313-345.

Kelly, M. (2009). A third space for Europe: Intercultural communication in European language policy. European Journal of Language Policy, 1(1), 1-20.

Kramsch, C. (1993). Context and culture in language teaching. Oxford: Oxford University Press.

Kramsch, C., \& Uryu, M. (2014). Intercultural contact, hybridity, and third space. In J. Jackson (Ed.), The Routledge handbook of language and intercultural communication (pp. 211-225). Abingdon: Routledge.

Phipps, A. (2014). 'They are bombing now': 'Intercultural Dialogue' in times of conflict. Language and Intercultural Communication, 14(1), 108-124.

Riitaoja, A. \& Dervin, F. (2014) Interreligious dialogue in schools: Beyond asymmetry and categorisation? Language and Intercultural Communication, 14(1), 76-90. 
Ritchie, J., Lewis, J., Nicholls, C. M., \& Ormston, R. (Eds.). (2013). Qualitative research practice: A guide for social science students and researchers. Sage.

Rutherford, J. (1990). The third space. Interview with Homi Bhabha. In J. Rutherford (Ed.), Identity: Community, culture, difference (pp. 207-221). London: Lawrence and Wishart.

Soja, E. W. (1996). Thirdspace: Journeys to Los Angeles and other real-and-imagined places. Oxford: Blackwell Publishing.

UNESCO. (2002). Universal declaration on cultural diversity.

Retrieved from http://unesdoc.unesco.org/images/0012/001271/127162e.pdf

Zotzmann, K., \& O’Regan, J. P. (2016). Critical discourse analysis and identity. In S. Preece (Ed.), The Routledge handbook of language and identity (pp. 113-128). London:

Routledge. 